\title{
PLACE IDENTITY AND SUSTAINABLE URBAN REGENERATION: PUBLIC SPACE IN CANBERRA CITY CENTRE
}

\author{
MILICA MUMINOVIC \\ Assistant Professor, Faculty of Architecture, University of Canberra, Australia.
}

\begin{abstract}
Urban regeneration projects often deal with activation of public space and pedestrian-oriented environments. That activation is based on idealisation of a good public space. It could be argued that our understanding of public space is deriving from the utopian ideas of democracy, ancient Greek agora and Roman forum. When we think about public space we usually imagine it as urban open space, accessible to all citizens, with ideal enclosed form of plaza of a particular size and scale, which welcomes everybody and demonstrates ultimate level of urbanity.

This paper uses the example of Garema Place in Canberra to discuss the interdependence of public space and place identity and their role in the regeneration of Canberra City Centre. Canberra is a planned city, with dominantly low density, dispersed town-centres, and nature as main element of its identity. The notion of public space and urban life differs from utopian ideas of agora and forum. The main character of Garema Place is noted within the nature. Yet the process of regeneration of Canberra city centre has been attempted within number of artistic and other public events, bringing people to the public space. The efforts to create a notion of plaza have not done much in generating the process of revitalisation. Garema still remains mainly vacant with low levels of street activities.

Because of different understanding of public space and place identity in Canberra, the paper hypothesises the need for a different kind of regeneration scenario. The discussion is drawn from an analysis of the character of Garema Place and history of public events in recent years in relation to the data of vacancy of built environment and everyday activities. The conclusion argues for importance of the place identity in the process of regeneration for more sustainable future of Canberra and its city centre. Keywords: place identity, public space, urban regeneration.
\end{abstract}

\section{INTRODUCTION}

The modernist approaches to design and planning of the cities and their public spaces in the 20th century, have contributed to erosion of public space. Problems arising from lack of activity in open public spaces, their sizes and car-oriented design of the cities are seen to create monotonous and underutilised spaces. Today, most of the cities designed on those modern principles are in the process of rethinking their public spaces and questioning the designer's role in creating the city. There is increasing number of regeneration projects focusing on the questions of public space and public life in those cities.

After planning and design approach in modernism, the theory has shifted towards learning from existing and successful cities, loved and liveable public spaces. There have been numerous studies on thriving spaces that can provide cases for better quality of public realm. The studies deriving from Jane Jacobs [1] and Kevin Lynch [2] have been further explored and tested particularly through examples of various successful regeneration projects around the world (see for example work by Jan Gehl). Learning from various cultures and bottom-up 
emergent spaces and testing those ideas at the regeneration projects have become dominant methodology for the urban design discipline. While, there are increasing numbers of studies that deal with successful public spaces that are emerging spontaneously, as bottom-up processes, one must ask what is the level of generalisation within those practices or how universal those principles are.

The design of public spaces presumes a particular idea of what these spaces should be. When we think of good public spaces, we think of Italian cities, beautiful plazas, people enjoying sun and socialisation. Although very successful, there are also cases in which those ideas might be difficult to implement. The current practice of revitalisation of existing public spaces is guided on the universal definitions of public space and on the successful examples of their implementation. The definitions of public spaces are deriving from the notions of democracy and examples of agora and forum. Not only that these examples refer to particular time in history of development of cities, but they also belong to a particular culture. Those ideas could be argued to present a kind of utopia. In some cases, they might serve as good striving points in revitalisation process while in others perhaps not. The fact that public space is considered to have a universal definition and fits every city and culture might be argued to be the reason for less successful revitalisation processes. Japanese language, just as an example, does not even have a Japanese word for public space. Urban design and planning does not recognise that the different cultures have different understanding of what public space should be.

In addition to the problem of diversity based on the cultural differences, changes in everyday life also contribute to the ways in which public spaces are being utilised. Gehl [3] distinguishes everyday activities in three groups: necessary, optional and social activities. Necessary activities are compulsory, and they are part of everyday routines (e.g. going to work or shopping etc.). The number of these activities that are conducted in public spaces has been reduced significantly in the 20th century. Going to work, for example, is in many cities conducted without a need to access the public space directly. Dominant mode of individual transportation allows for the extension of private sphere and thus people spend less time in public space as part of their everyday routines. Optional activities are those conducted in leisure time (e.g. walking for fresh air, stopping for coffee etc.). The number and duration of these activities are increasing in the last century, particularly as part of the consumerist culture. As the result designing spaces for optional activities become dominant element of the regeneration projects. However, they are often happening in indoor spaces (shopping malls, gyms, etc.) therefore leaving little room for the activities in open public spaces. Social activities are based on the social behaviour and depend on the presence of other people (e.g. various kinds of passive contacts, communal activities, conversations etc.). Those activities are important part of the everyday life; however, they are usually part of organised events, missing the spontaneity of everyday life. The lack of necessary activities [4] and the size and quantity of available spaces complicates the current tendencies of returning the public space to the human.

Not only that the different cultures have their own definitions of public spaces, and the changes in everyday practices that create challenges for public spaces, but also spaces designed on the ideas and ideals of modern cities are providing a new, modern definitions of public space. Planned cities such as Brasilia, Chandigarh and Canberra demonstrated a different set of challenges for planners and designers and regeneration projects. The whole concept of public spaces in these cities is based on the vague ideas of modern society, which presumed that the modern human would have a different set of desires in everyday life. At the 
beginning of 20th century planers believed that new technologies would produce strong changes in everyday life. The new modern human was then supposed to enjoy a different kind of public space. The fact that mobility was dominantly designed around the car in those projects has created additional challenges. Dominated by car the public spaces were eroded as a result of their size and overall unattractiveness, they are left underutilised. The presumptions of new needs for modern man and women have shown to be wrong. Humans still desire socialisation and public spaces for interaction and bodily experiences. The solutions of revitalisations of public spaces highly depend on the sizes and possibility of utilisation as well as the attractiveness of public spaces. The fact that in such cities there is a vast amount of open space that is considered to be public is creating additional issues. The transformation processes of such cities are slow and questionable. So, how to bring back those spaces to the human, and bodily experience?

This paper aims to discuss an example of public space that was designed based on the modern principles and proposes an approach to revitalisation of public space. The paper uses an example of Canberra, a designed city that has all the issues that emerge from the modern planning. The selected case study of Garema Place is used as an illustration to demonstrate the complexity of the problem of revitalisation with an attempt to discuss that issue in this paper within the meaning of public space. The revitalisation attempts of Garema Place to this date have been only partially successful. The main argument is that we have to redefine the meaning of public space based on the specificity of culture and to look at the space in its full complexity. To do so, paper proposes the methodology based on the place identity. Using the example of Canberra the paper hypothesises that the understanding of urban in this city is linked to the landscape and natural, therefore the public space in traditional sense does not work.

\section{THE GOOD PUBLIC SPACE}

The questions on how to build good public space have been addressed throughout the whole history of city making. Various approaches to design of public space are characterised by shifting their focus between the formal and social aspects of the city. Tangible characteristics of built environment are important for creating good public spaces. However, the intangible aspects such as meanings and activities are seen to be also very important for designing successful places. Meanings and activities in space are formed over time and they often emerge as part bottom-up processes. Those processes are necessary part of city and demand a level of spontaneity to be successful. The mix between planned and spontaneous aspects of the city is both important for success of the public space.

\subsection{The form}

Dominantly formal approach deals with spatial aspects of built environment and proposes that particular size, scale, shape and their design are main elements in defining the good public space. For example, Camilo Sitte [5] was exploring the existing public spaces and created a set of formal rules of good design strategies of public spaces based on the analysis of number of medieval towns in Europe. According to this study the proper size, scale and geometry of public space were main elements to determine the quality of open public space. Sitte argues that the essential qualities of the public antique spaces are persisting within public spaces in medieval period, determining the universal aspects of public space.

As a result of industrial revolution, population growth in the cities and congestion the planning at the beginning of 20th century has attempted to approach cities in new unique ways. 
Instead of praising antique or medieval successful public spaces, planning practice has turned to defining the new and modern cities. Solving the problems of congestion and lack of space, public spaces have become dominantly green spaces. The traditional ideas of street and square have lost their character and role as main socialising and political spaces. Public spaces have become spaces for the fresh air and recreation. For example, Garden cities and Le Corbusier's metropolis have both in their own ways transformed the open public spaces by introducing new transport technologies to the cities [6]. Those new public spaces have turned to vast green areas and parks. The socialising activities have been in those cities shifted from open public to the interior spaces.

\subsection{The activities}

The second approach to design of good public spaces deals with activities that are performed in the public realm. During the 20th century planning and design of the cities the approach to the activities has been focused on the modern human. Public space has been defined according to the visionary ideas about the future public spaces and changes that the new technology was about to bring. Le Corbusier in his writings imagines new kinds of activities for new, modern man and designs the spaces for all those activities [7]. After those unsuccessful examples, the focus has been shifted towards the traditional activities. Jane Jacobs has turned the attention to the traditional functions and activities in both open public spaces and the buildings around.

The importance of both function and form are recognised in the contemporary approach to design of public spaces. Jan Gehl discusses the importance of both, function and form, particularly at the examples of edges between the public and private realm [3,8]. The most important elements are regarded to human scale and activities conducted within those spaces. The contemporary theoretical and design approaches to good public spaces are usually dominated with the particular set of rules related to comfort and image, access and linkage, uses and activity, and sociability [9]. These approaches are designing the public spaces in isolation to the wider network of public spaces in the city as well as the ways in which they interact with the city as whole. In many cases, the problems of public spaces are seen as urban problems solved at the level of aesthetics or mere activities in space. In addition, those approaches are referring to the public space as set of the universal characteristics that are applicable to any location. This approach simplifies the problems that we are dealing with in the cities and could be argued that it is the reason for less successful revitalisation processes. There is a need for holistic and more complex approach to design and planning of public spaces. The potential approach that will observe public space in its full complexity that this paper proposes is based on place identity.

\section{METHODOLOGY AND METHODS}

This paper proposes the analysis of public spaces from the place identity perspective. In order to set and test the methods for revitalisation of public space, this paper will present a short review of the definitions of place identity and further develop methods and test them at the case study of Garema Place.

Place identity refers to a quality of a location and expresses the complex relationships between all the elements of the place. It is a territorialised assemblage of people and environment deriving from both material and experiential dimensions of a location [10]. Every place has an identity, which can be more or less developed. Over time, identity of any place changes. 
Since places are assemblages '.... whose properties emerge from the interaction between parts' [11], then the place identity represents all the elements of a location and their complex relationships. Those relationships refer to both relationships between elements that constitute a place (relationships of interiority) and how they interact with elements outside of the assemblage (relationships of exteriority) [11].Thus, the identity emerges from interaction between all the elements and cannot be reduced to one of them. This characteristic of identity represents the reason for its utilisation as a method within the process of revitalisation of public spaces.

Another important characteristic of the place identity observed as assemblage that differentiates this approach from current approaches to revitalisation of public spaces is related to multi scalar analysis. When location is observed within aspects of identity it implies relationships between elements that are interacting at various scales. Those relationships could be 'logically necessarily', but also 'contingently obligatory' [12]. Those relationships are never defined hierarchically, but as 'non-linear causality' as complex relationships of micro-macro scales [11]. Thus, revitalisation process that is based on the place identity inevitably considers public space as part of the complex assemblages of all public spaces in the city.

Identity also refers to the quality and uniqueness of any location. For a location to be a place and thus be meaningful part of everyday life it has to possess a certain kind of identity [13]. The identity is formed over time and distinguishes a place as authentic in relationship between people and locality. Place identity defines the uniqueness of a location compared to all other places (its synchronic dimension). It comprises all the invariable qualities and characteristics of a location, both tangible and intangible, defining its essence. Thus, each location has its own qualities and characteristics that need to be considered within the process of its comprehension and design. In addition, identity refers not only to the current state of the location (its character) but also comprises in itself a history of that location (its diachronic dimension).

Important aspect of place compared with a location is in the ability of people to relate to the place. Namely, the location becomes a place only through peoples' ability to dwell in that location, demonstrated through building. By dwelling in a location people appropriate the place, interact and develop attachments. This could be argued to be an important quality of any place, thus public place as well.

Identity represents a complex concept that comprises both tangible and intangible aspects of location, its built environment, meanings and activities [14]. Place identity is built on the complexity of the relationships between all different elements of the place as assemblage [10]. These characteristics of relationships of interiority and exteriority as well as multiple scales and the causality between them, are important elements in defining the principles for the proposed methods in this paper. The identity represents emergent quality based on the complex relationships of all elements of place. Since identity comprises all the aspects of place, then by analysing the public space using the concept of place identity this paper hypothesises that this method will provide a better insight into the revitalisation process.

The method derives from place theory and assemblage theory. The paper proposes an analysis of the place identity as the main element that will enhance the design of public space. The first stage of the analysis, which is the focus of this paper, is related to the analysis of the phenomenon of Garema Place. In other words, the analysis focuses on understanding the ways in which current public space is experienced. The second part of the analysis would be to understand the tangible aspects of the place, which will not be part of this study. The 
analysis of phenomenon of Garema Place will follow two steps. Firstly, analysis of the place identity will be based on the discourse analysis to define the main elements of its identity. Secondly, those elements will be compared with the actions that were taken in Garema Place for its regeneration.

\section{THE CASE OF GAREMA PLACE IN CANBERRA}

The city of Canberra is a good example of 20th century planning that continues to grow and seeks for redefinition of its public spaces. The city begins its development after the plan developed by Walter and Marion Griffin, a winning scheme of international competition that was organised in 1911 [15]. The city was envisioned as the new capital of the nation, an ideal city based on the main Garden City principles and City Beautiful movement [16]. The plan of the city was envisioned around monumental representations of the nation, as the city needed to embody the identity and integration to the landscape [17]. The importance of the physical features of the site was recognised from the very beginning. Griffin's plan embodied the natural elements of the landscape as part of the planning and design [18]. The rigid geometry of the city, based on the triangular axis produced monumental vistas to the surrounding mountains introducing the sky and the nature to the scenery. The first works on the new capital of Australia began in 1913.

The city of Canberra was envisioned around the triangle of three major functions that were meant to represent the centre of the city [19]. On the southern side of the lake, Griffin envisioned Government Zone, while the other two sides of the triangle located north of the lake were dedicated to municipal functions (administrative and mercantile). Those zones are today devoted to offices and mercantile functions in Civic and war memorial on the other side dedicated to the memory, ceremonial space and identity of the nation. Garema Place represents the part of the Civic zone.

The Civic started developing its business activities in 1926 with the light industry buildings as well as the shopping arcades of Sydney and Melbourne building just at the beginning of Northbourne Avenue. During 1930s and 1940s the development of this area was slowing down with the building of a Civic Hotel as the only major project during those years. The population was growing after the Second World War and Civic area has also saw an increase in number of young families. During that period child welfare centre, a restaurant and cafe were built. Within the same period the National University of Australia has begun its development. Only in the 1960s the growth of this area was accelerated within focus on the office buildings, shopping mall and Canberra Theatre. For the period of 1970s part of Alinga Street has been closed for pedestrians, which became the City Walk, an area that represents an extension of Garema Place. The whole area of Civic continued to develop in next two decades as the major commercial and business centre in Canberra. Today, Garema Place still strives to become a representative centre of the city. The commercial activities, proximity of the main bus interchange, numerous restaurants and bars create the basis for this area to take the role of the city centre. In addition to diverse activities Garema Place offers a human scale in terms of its size. It is enclosed space with small scale and diverse edge, offering the opportunities for commercial activities [20].

Despite the fact that there are important elements for Garema Place to function as a successful public space, this is still not happening. As the Property Council CEO Catherine Carter has pointed out recently, that is yet to come. 'Despite strong desire among the community, and despite multiple government reports promising action, we are yet to see any meaningful, positive change in our city centre' [21]. 


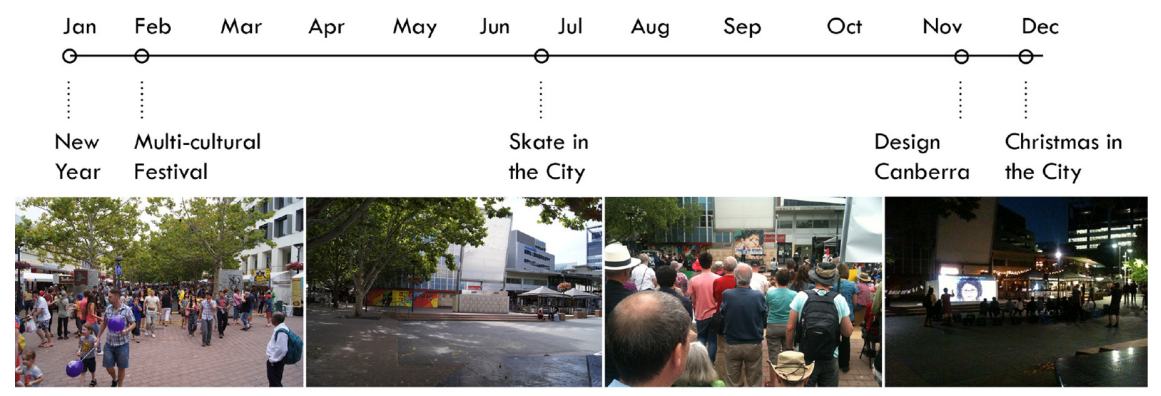

Figure 1: Timeline of major events at Garema Place.

Latest report on Canberra's city centre demonstrates the disappointing results despite numerous attempts to revitalise this area. The vacancy of the office space has seen a constant increase in the last 5 years to $12 \%$ together with the City Walk at 19\% [22]. The number of vacant spaces, particularly at the pedestrian level, demonstrates the problems that Garema Place faces in terms of its public life.

The numerous events, which are organised in this space during the year, also represent an attempt to revitalise this space. All those events are very successful, with high number of visitors, however only while they last. They don't have any permanent impact to changing conditions of Garema Place (Fig. 1).

\section{ANALYSIS AND RESULTS}

In order to understand why current revitalisation attempts of Garema Place do not show any significant results, this paper proposes to analyse the place from the identity perspective. The analysis is conducted at two scales, the scale of the whole city and the neighbourhood scale. The analysis of the place identity is based on the phenomenological approach. The results of the whole city scale are deriving from the results summarised in the survey conducted in 2013 as part of celebration of hundred years of the city.

In 2013, marking the hundred years of its existence was seen as the time to recapture and mark the path of the city in the next 20 years. The report 'Time to Talk' summarises the way community perceives Canberra. City has been in most of the cases described with the keywords: bush, friendly, clean, family, open, home, capital [23]. This report demonstrates that main characteristic of the city or the identity of the place is still bound with the nature. One of the main challenges for the future development of the Canberra was defined within retaining the liveability, traditional community spirit and 'Bush Capital' character [23].

The second stage of the analysis considers the identity of Garema Place. Since identity is defined as phenomenon the analysis is based on the question on how people experience the space. More specifically, it asks the question of what is the most essential element of the space that generates the strongest experience.

Discourse analysis of the Garema Place has been conducted during the February 2015 with the 135 design students at the University of Canberra. As part of the first exercise in Design Studio 1.1 at University of Canberra (Table 1) students were asked to spend two hours at the Garema Place and distil their experience of the place verbally in short description and visually using any graphical methods (Fig. 2). The experience of the place was 


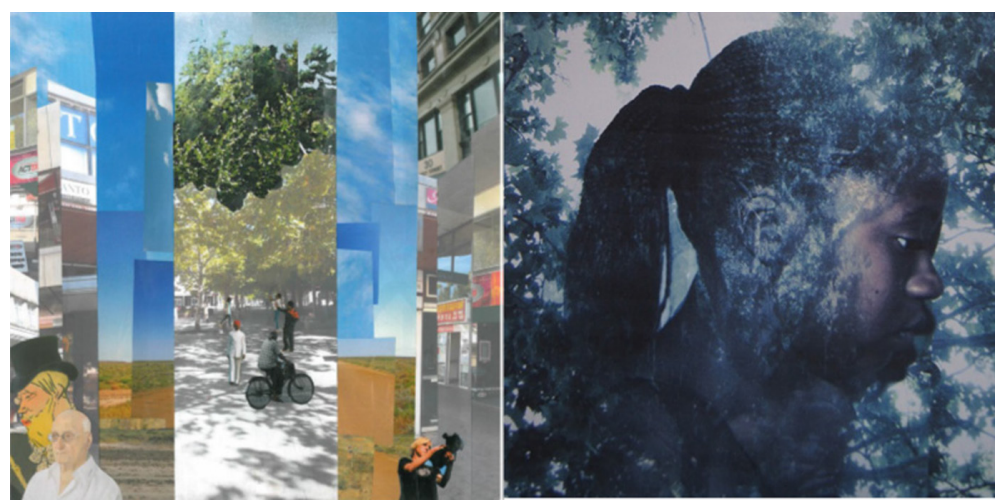

Figure 2: Examples of student visualising experience of Garema Place (Bess Laaring and Sika Manteaw).

Table 1: Design Studio 1.1 instructions for data collection.

\begin{tabular}{ll}
\hline Method & MO1 Experience \\
\hline $\begin{array}{l}\text { Instructions for the } \\
\text { experience }\end{array}$ & In this module, you will be learning how to capture experiences \\
from the space and represent them using various techniques. \\
Instructions: \\
Document spatial experience of a journey within selected \\
location, travelling from one place to another. Prepare map that \\
shows the journey. Experience can be recorded in open space \\
or interior following elements such as: materials, light, texture, \\
solid, void, geometry, emotion, nature, colours, smell, ground, \\
sky, etc. \\
Presentation media: photos, measurements, sketches, collage, \\
models, movies, recording sounds, writing, etc. \\
Prepare a short explanation (2min) for the studio- try to distil \\
your experience in couple of key words \\
\hline
\end{tabular}

conducted during the weekdays on the ordinary days (avoiding the events in January and February). The reason was to capture the experience of the space during its lowest peak of activity.

The results were based on collection of keywords as part of the exercise. Students were not limited with the number of keywords, and the average range was from three to five. Sum of all keywords shows that the most dominant element that students refer to as the strongest experience in Garema Place can be grouped in four sections: nature, people, built environment and atmosphere. Nature group was most numerous appearing in 51\% of the student work. In addition the number and diversity of the phenomena was largest in this group. The nature group was followed with various elements of built environment (24\%), people (15\%) and atmospheric elements (10\%). The main qualitative determinants of the nature were always followed with positive emotions while built environment was usually mentioned within the negative notions of the place. Atmospheric elements and people were considered as both positive and negative aspects of the experience (Table 2). 
Table 2: Summary of all keywords.

\begin{tabular}{llll}
\hline Nature & People & Built environment & Atmosphere \\
\hline birds singing & flow & buildings & light/shadow \\
foliage & movement & colour & sound \\
fountain/water & open & facades/ rhythm & uniform \\
greenery & excited & pavement & \\
green colour & busy & public art & \\
shape of trees & & shops/ signs & \\
sky & & stainless steel & \\
tree & & textures & \\
balanced & & & \\
calm & & & \\
peaceful & & & \\
relaxed & & & \\
tranquillity & & & \\
\hline
\end{tabular}

\section{CONCLUSION}

The analysis of the way in which people experience Canberra and Garema Place has demonstrated that the most important element of the space is nature. Even before any plans of the city were in place, before considering the location, the landscape was regarded as the most important element of the future capital [18]. Following that, Wlater Burley Griffin's plan for the city of Canberra was believed to have sensitive approach to existing physical features of the site: mountains, water as well as 'monumetalising the nature' (ibid: 135). Thus from the very beginning, the nature, becomes leading element of the identity of the national capital, also called The Bush Capital. That element is important, as it links the identity of the place to indigenous characteristics of the locale, those that reach far back than the ones of the colonial times and in the same time reaching towards the English cultural elements of the picturesque.

All the previous efforts to revitalise Garema Place have attempted to focus on designs that are defined on the universal meaning of public space. Numerous events organised throughout the year and developing Garema Place as shopping hub of the city were unsuccessful. The uniqueness of Garema Place was never part of the design process, in most of the cases the inspiration is sought from Melbourne or other successful examples around the world. Although, multiple events and design strategies are mapping this space as important part of the public life, the Garema Place remains outside of the public image of Canberra.

The results from this pilot study of Garema Place as a phenomenon and assemblage have indicated a mismatch between the definitions of the public space and regeneration design strategies. While all the revitalisation projects set as a goal for Garima Place to become enjoyable public space none of them addresses the uniqueness of the definition of that public space. What does it mean in the planed city, highly dependable on a car and with vast open spaces to have a public space? This short analysis demonstrates that to have a sustainable revitalisation approach to public spaces we need to reconsider the definition of the public space and uniqueness of each location and culture.

In the broadest sense, Garema Place opens questions on necessity for revitalisation process to come from the place itself. Revitalisation projects demand a response to the complexity of 
the city and in the same time to the specificity of each location. Place identity can be considered as important tool in achieving those goals, as it comprises in itself a full complexity of the city.

\section{REFERENCES}

[1] Jacobs, J., The Death and Life of Great American Cities, Vintage Books: New York, 1961.

[2] Lynch K., The Image of the City, MIT Press: Cambridge, MA, 1960.

[3] Gehl, J., Life between the Buildings: Using Public Space, Arkitektens Forlag: Skive, 1996.

[4] Gehl, J. \& Gemozoe, L., Public Spaces- Public Life, The Danish Architectural Press: Copenhagen, 1996.

[5] Sitte, C., The Art of Building Cities, Hyperion Press: New York, 1945.

[6] Fishman, R., Urban Utopias in the Twentieth Century : Ebenezer Howard, Frank lloyd Wright, and le Corbusier, MIT Press: Cambridge MA, 1982.

[7] Corbusier, L., The City of to: Morrow and its Planning, The Architectural Press: London, 1971.

[8] Bobic, M., Between the Edges, Street-building Transition as Urbanity Interface, THOTH Publishers: Bussum (The Netherlands), 2004.

[9] Carmona, M., Tiesdell, S., Heath, T. \& Oc, T., Public Places Urban Spaces, the Dimensions of Urban Design, Routledge: London and New York, 2010.

[10] Dovey, K., Becoming Places, Urbanism/Architecture/Identity/Power, Routledge: London and New York, 2010.

[11] Delanda, M., A New Philosophy of Society-Assemblage Theory and Social Complexity, Continuum: London and New York, 2006.

[12] Delanda, M., Intensive Science and Virtual Philosophy Continuum: London and New York, 2002.

[13] Norberg-Schulz, C., Genius Loci Towards a Phenomenology of Architecture, Rizzoli International Publications: New York, 1980.

[14] Relph, E., Place and Placelessness, Pion Limited: London, 1986.

[15] Watson, F., A Brief History of Canberra the Capital City of Australia, Federal Capital Press: Canberra, 1927.

[16] Headon, M., An ideal city. Canberra Red, Stories from the Bush Capital, eds. D. Headon \& A. MacKenzie, Allen and Unwin: Sydney, pp. 61-84, 2013.

[17] Taylor, K., Canberra. City in the Landscape, Halstead Press and The National Capital Authority: Canberra, 2007.

[18] Vernon, C., Canberra: where landscape is pre-eminent. Planning Twentieth Century Capital Cities, ed. D. Gordon, Routledge: London and New York, pp. 130-149, 2006.

[19] Cleary, A. \& Geleris, P., Civic Revealed, a Community Profile, ACT Planning Authority: Canberra, 1996.

[20] Civic Centre Canberra Policy Plan. Implementation Plan, National Capital Development Comission: Canberra, 1987.

[21] Carter, C., Time to "turn on and transform civic" says canberra business groups, Property Council of Australia: Canberra, 2015.

[22] Transforming canberra city cntre, The Property Council of Australia and City Canberra CBD LTD: Canberra, 2015.

[23] Time to talk canberra 2030, ACT Government: Canberra, 2010. 